\title{
The Effect of Training on Functional Behavioural Analysis on Teacher Self-Efficacy Among Special Education Teachers in Osun State, Southwestern Nigeria
}

\author{
Olanrewaju Ibigbami ${ }^{1}$, Yetunde Adeniyi ${ }^{2}$, Olayinka Omigbodun ${ }^{3}$ and Cornelius Ani ${ }^{4}$ \\ ${ }^{1}$ Department of Mental Health, Obafemi Awolowo University lle-Ife and Consultant Child and Adolescent Psychiatrist, \\ Wesley Guild Hospital Unit, Obafemi Awolowo University Teaching Hospital Complex, llesha, Nigeria \\ ${ }^{2}$ Centre for Child and Adolescent Mental Health, College of Medicine, University of Ibadan, \\ Consultant Child and Adolescent Psychiatrist, University College Hospital Ibadan, Nigeria \\ ${ }^{3}$ Centre for Child and Adolescent Mental Health, College of Medicine, University of Ibadan, \\ Consultant Child and Adolescent Psychiatrist, University College Hospital Ibadan, Nigeria \\ ${ }^{4}$ Division of Psychiatry, Imperial College London, and Consultant Child and Adolescent Psychiatrist, \\ Surrey and Borders Partnership NHS Foundation Trust, UK
}

\begin{abstract}
HOW TO CITE:
Ibigbami, O., Adeniyi,

Y., Omigbodun, O., Ani, C. (2020).

The Effect of Training

on Functional Behavioural Analysis on Teacher

Self-Efficacy Among Special

Education Teachers in Osun

State, Southwestern Nigeria.

International Journal of Special

Education, 35(2), 73-82

CORRESPONDING AUTHOR:

Ibigbami Olanrewaju;

oibigbami@oauife.edu.ng

DOI:

https://doi.org/10.52291/

ijse.2020.35.15

\section{COPYRIGHT STATEMENT:}

Copyright: (C) 2020 Authors.

Open access publication under the terms and conditions

of the Creative Commons

Attribution (CC BY)

license (http://creativecommons. org/licenses/by/4.0/).
\end{abstract}

\section{ABSTRACT}

Dealing with challenging behaviour is a source of stress and burnout among teachers of children with special education needs. Functional Behavioral Analysis (FBA) is useful for prevention and management of challenging behaviour, but the evidence-base among special education teachers is limited in Sub-Saharan Africa. Twenty teachers were recruited from two special needs schools (10 from each school), with one school designated 'intervention' and the other 'control'. Two sessions of group-based training on FBA were conducted in the intervention school for the 10 teachers. All participants completed the 'Teacher Self Efficacy Scale' and 'Professional Quality of Life Scale' at baseline and again two weeks after the last intervention session. The intervention group completed a post-intervention 'Client Satisfaction $\mathrm{Qu}$ estionnaire'. Controlling for baseline scores, the intervention group scored significantly higher on Self-Efficacy $[F(1,18)=8.95, p=0.009$, partial eta squared $=0.36]$, and lower on Burnout $[\mathrm{F}(1,17)=9.82, \mathrm{p}=0.006$, partial eta squared $=0.380]$. The intervention group's mean score on the Burnout subscale of PQOLS was more than one standard deviation lower than the control group after the intervention [(29.30(2.58) vs 34.11(4.01)]. All participants in the intervention group rated the programme as good or excellent and over three -quarters $(77.7 \%)$ would recommend it to their peers. To our knowledge, this is the first study of FBA training for special education teachers in Sub-Saharan Africa. The programme showed promising effectiveness, good feasibility and was highly accepted.

Keywords: Functional Behavioural Analysis; Special Education Needs; Burnout; Teachers; Nigeria 


\section{INTRODUCTION}

Special education teachers play crucial roles in meeting the scholastic needs of children with intellectual and developmental vulnerabilities (Hillel Lavian, 2015). These teachers' roles can be both rewarding and challenging (Robinson et al., 2019). Working with children with special needs to achieve their optimum educational development can be a professionally satisfying experience (Hillel Lavian, 2015). However, the work can also be emotionally and physically demanding because affected children often have psychiatric and medical disabilities associated with challenging behaviours (Langher et al., 2017). Studies show that challenging behaviours are among the most common sources of stress and attrition among teachers (Brunsting et al., 2014). However, the extent to which special needs teachers experience stress due to students' problematic behaviours varies between teachers. The differences may relate to environmental factors such as adequacy of classroom resources and or individual teacher factors such as their self-efficacy (Zee $\&$ Koomen, 2016).

Teachers' self-efficacy is the belief that a teacher has about their capabilities to achieve particular educational outcomes (Lunenburg, 2011). The concept relates to theories about human agency such as Rotter's theory on locus of control (Rotter, 1966), and Bandura's social cognitive theory (Bandura, 1991). These underpinning theories postulate that teachers with higher self-efficacy would tend to perceive outcomes to be contingent on their own actions, and believe that they have the ability to carry out such actions. Importantly, self-efficacy is dynamic (Mencl et al., 2012), which means that teachers' self-efficacy can be improved by additional training and skills development (Zee \& Koomen, 2016). Studies have shown that improving teacher self-efficacy is associated with a wide range of positive outcomes including use of more effective strategies for managing students' challenging behaviours (Zee \& Koomen, 2016).

Bandura's theory of reciprocal causation (Bandura, 1986) suggests that teacher's self-efficacy may have a bidirectional relationship with certain students' attributes such as challenging behaviours. Thus, while teachers with high self-efficacy may be better able to manage their students' challenging behaviours, the opposite could also be true whereby high levels of students' challenging behaviour could undermine teachers' self-efficacy. This interaction may be particularly pertinent for special edu- cation teachers given that they work with students whose psychiatric and developmental difficulties increase their propensity for challenging behaviours (Brunsting et al., 2014). Thus, the ability to manage challenging behaviours appropriately and confidently is a crucial skill for all teachers; more so those working with children with special needs (Hillel Lavian, 2015). This is important not only because challenging behaviours place the affected children and their peers at risk of physical and emotional harm, but also because such behaviours can also be detrimental to teachers' well-being and self-efficacy, and increase their risk of burnout (Brunsting et al., 2014).

One of the effective strategies for managing challenging behaviours is Functional Behavioural Analysis (FBA) (Lloyd et al., 2016). FBA is a systematic process for identifying the purpose of challenging behaviours, which helps to inform interventions to prevent and address the maladaptive behaviours (Foran et al., 2015). Recent systematic reviews provide good support for the effectiveness of FBA in reducing students' challenging behaviours across different types of schools and classroom settings, and when delivered by a range of personnel (Heath Jr \& Smith, 2019; Lloyd et al., 2016). Thus, both the underpinning theory of FBA and the evidence-base for reducing challenging behaviours in children with developmental difficulties are now well established. However, this evidence-base is largely based on studies in High Income Countries (HICs) as shown by the fact that none of the studies cited in recent systematic reviews (Heath Jr \& Smith, 2019; Lloyd et al., 2016) were from Africa. Although one recent study from Nigeria (Bello-Mojeed et al., 2016) showed the feasibility of parent-delivered FBA-based strategies in reducing challenging behaviours among children with autism spectrum disorder; the evidence-gap from Low and Middle Income Countries (LMICs) on FBA remains very wide.

The huge socio-cultural and resource differences between HICs and LMICs mean that interventions which are successful in HICs should not be assumed to be as effective, or acceptable in LMICs; without further local contextualization (Craig et al., 2013; Sweetland et al., 2014). Incidentally, LMICs have a higher proportion of children with special education needs, but very few teachers adequately trained to work with affected children (Olusanya et al., 2018). This imbalance of need and resource is a recipe for stress among teachers in this region, which can only be exacerbated by students' challenging behaviour. This is more so if teachers are not adequately 
equipped with strategies for prevention and management of challenging behaviours. Therefore, if it can be evidenced that training special needs teachers in this setting on FBA can improve their knowledge and self-efficacy in managing students' challenging behaviours; the outcome could lead to wide-ranging benefits for teachers and students, as well as policy makers in the region.

Thus, the aim of this pilot study is to determine the effect of an FBA-based training for special educational needs teachers on the teachers' self-efficacy and quality of life. The underpinning hypothesis is that improving the teachers' knowledge of FBA will improve their belief in their own ability to manage challenging behaviours; hence better self-efficacy. Furthermore, the study explored feasibility parameters such as 'deliverability' and acceptability of FBA, which could inform future definitive trials in the low-resource context of Nigeria. Given the very limited number of studies on FBA in the region, this study contributes towards enhancing the diversity and inclusivity of the global literature on FBA.

\section{METHODS}

\section{Study design}

This was a two-group intervention study with an "intervention" group and a "control" group, conducted in two publicly-funded primary schools in Osun State, Southwestern Nigeria. Two of the nine publicly-funded primary schools for children with special education needs in Osun State were purposely selected based on ease of access and the distance between them. The two schools were 35 kilometers apart, which reduced the potential for "intervention contamination". Balloting was used to designate the school at Ilesha as "intervention" while the school at Osogbo was "control".

\section{Participants and recruitment}

The participants were 20 fully qualified special educational needs teachers. All 10 teachers in the intervention school were recruited, while balloting was used to select 10 out of 20 teachers in the control school. All selected teachers consented to participate in the study and completed the baseline measures. All the teachers in the intervention group completed the two training sessions. One teacher in the control group was not available for the post-intervention evaluation (see Figure 1).

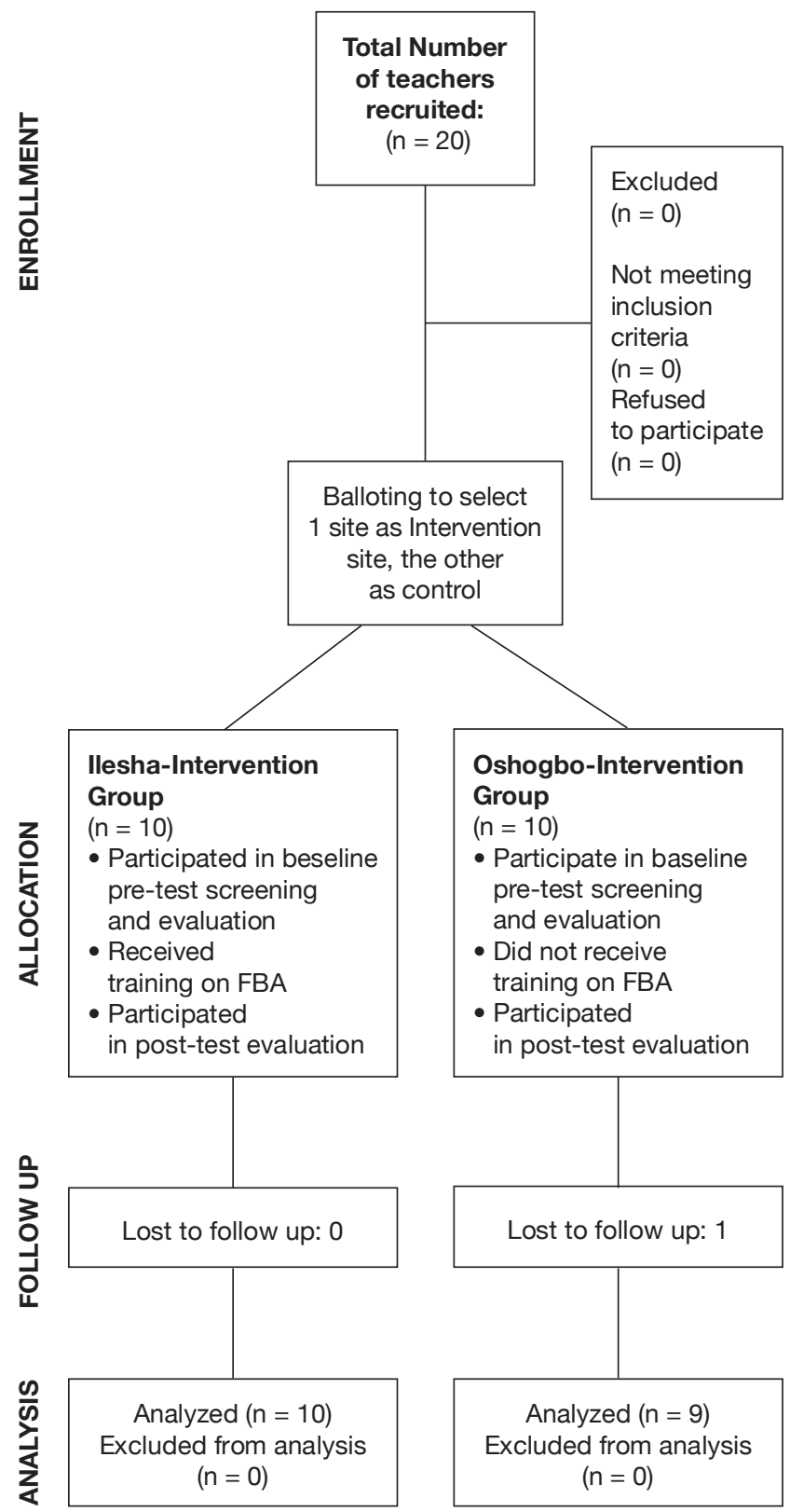

Figure 1.

FBA Intervention Flow Diagram

\section{Measures}

The study instruments included (1) Socio-demographic and Professional Experience Questionnaire (2) Teacher Self-Efficacy Scale (Tschannen-Moran \& Hoy, 2001), (3) Professional Quality of Life Scale (Stamm, 2010), and (4) Client Satisfaction Questionnaire.

\section{Socio-demographic and Professional} -Experience Questionnaire: This consists of: questions relating to the teachers' age, gender, marital status, number of years in service, previous training in the management of challenging behaviours or FBA, area of specialty and highest qualification (as shown in Table 1). 
Teacher Self Efficacy Scale (TSES): The TSES is a 24 item instrument (Tschannen -Moran \& Hoy, 2001) with three sub-scales: Efficacy in Student Engagement, Efficacy in Instructional Practices, and Efficacy in Classroom Management. It is designed to elicit information on the factors that cause difficulties for teachers in the course of their duties. The items are rated on a 9-point Likert scale ranging from "nothing" (1) to "a great deal" (9). The total and sub-scores are derived as sums of all, or the relevant sub-scale items respectively. Higher total or sub-scores are indicative of better self-efficacy. The internal consistency for the entire scale in this study population was 0.88 . The internal consistency for the sub-scales were;:Student Engagement 0.65, Instructional Strategies 0.74 and Classroom Management 0.72. The instrument has previously been adapted and used among teachers in Southwestern Nigeria (Durowoju \& Onuka, 2015).

Professional Quality of Life Sca$\operatorname{le}(\operatorname{ProQOL}):$ The ProQOL is a 30 item scale that measures the level of quality a person feels in relation to their work with regards to providing help or support for others (Stamm, 2010). The instrument has three sub-scales namely: Compassion Satisfaction, Burnout, and Secondary Traumatic Stress. Burnout and Secondary Traumatic Stress are combined to create a measure of "Compassion Fatigue". A score of 43 or less signifies the low point on any of the scales, a score of 50 is average, while scores above 57 are considered high. Higher scores for Compassion Satisfaction imply a better capability at being a caregiver or improved efficiency in the execution of duties. Higher burnout implies a greater level of difficulty for the person doing the job, which also puts the individual at a higher risk of hopelessness due to inability to meet set goals. Higher Secondary Traumatic Stress indicates that the subject is being exposed to high-levels of stressful and traumatic events. While this does not imply that the individual has a problem, it is an indication for a review of the work environment. Internal consistencies of $0.87,0.72$ and 0.80 have been reported for the respective sub-scales, (Stamm, 2005). The scale has been used successfully among Nige- rian mental health professionals (Adeyemo et al., 2015; Joyce et al., 2016).

Participants' Knowledge About Challenging Behaviours and FBA: To determine the participants' knowledge about challenging behaviours, they were asked to provide a 'free-text' answer to the question "What are Challenging Behaviours?". Their responses were rated in similarity to the definition by Emerson and Bromley (1995) "culturally abnormal behaviour(s) of such intensity, frequency or duration that the physical safety of the person or others is placed in serious jeopardy, or behaviour which is likely to seriously limit or deny access to the use of ordinary community facilities"(Emerson \& Bromley, 1995). The responses were graded across 4 levels as follows: "No attempt", "Poor Attempt", "Fair Attempt" and "Good Attempt". Similarly, the participants were asked to provide a free-text answer to the question: "What is Functional Behavioral Analysis?". Their responses were similarly rated against the definition by Iwata et. al. (2000). "an investigatory procedure derived from the applied behavioural analysis that provides a process for the determination of the purpose or reasons for behaviours displayed by individuals with cognitive or communication disabilities" (Iwata et al., 2000). For responses to both questions, the grading was done by a consensus reached by two psychiatry residents who were blinded to the study hypothesis and group allocation.

Client Satisfaction Questionnaire: This was adapted from the instrument developed by Atkinson and Greenfield (2004) and used to ascertain the intervention groups' experience of the program. It is an 8 item questionnaire scored on a Likert scale of 1-4 based on various aspects of the intervention. This has been used successfully in other intervention studies in $\mathrm{Ni}$ geria (Bella-Awusah et al., 2016; Bello-Mojeed et al., 2016)

\section{Ethical Considerations}

Ethical approval was obtained from the Ethical Review Committee of the State Specialist Hospital Osogbo, and permission to carry out the training was granted by the Ministry of Education, Osun State. All participants provided written consent. 


\section{Intervention procedure}

The intervention was adapted from an existing manual for the training of school-based personnel (Loman \& Borgmeier, 2010). The first author delivered the training in a group format to the 10 teachers in the intervention group. It involved two sessions (each lasting 2 hours) delivered weekly during planned break periods from their teaching responsibilities. The first session provided an overview of challenging behaviours, including possible triggers among persons with special education needs. The second session focused on the principles and application of FBA. The sessions included practical examples and role-plays as outlined in the manual (Loman \& Borgmeier, 2010). The control group had one session consisting of; a general discussion about their work and the challenges they experienced as teachers working with students with special education needs. The session with the control group did not include FBA. There was no evidence at the post -intervention assessment that the control group had been exposed to the training on FBA. Both the intervention and control groups completed the baseline measures before the intervention and the post-intervention measures
( 2 weeks after the last intervention session). In addition, the intervention group completed the client satisfaction questionnaire along with the other post-intervention measures. The project was completed in a month.

\section{DATA MANAGEMENT}

Data analysis was carried out using 'Statistical Package for the Social Sciences version 20' (SPSS - 20). Scores on continuous outcome measures such as self-efficacy and burnout were sufficiently normally distributed to permit parametric analysis. Thus, they were summarized using Means and Standard Deviations. A T-test was used to compare normally distributed continuous measures across dichotomous categorical variables (e.g. intervention group versus control group) and a Chi-square method was used to test for associations between categorical variables. Within-group comparisons of mean scores on the baseline and post-intervention outcome measures were conducted separately for the intervention group and control group using a paired sample T-test. Differen-

Table 1.

COMPARISON OF SOCIO-DEMOGRAPHIC VARIABLES ACROSS INTERVENTION AND CONTROL GROUPS

\begin{tabular}{|c|c|c|c|}
\hline Parameters & $\begin{array}{l}\text { Intervention } \\
\text { Group }(\mathrm{N}=10)\end{array}$ & $\begin{array}{c}\text { Control } \\
\text { Group }(\mathrm{N}=10)\end{array}$ & X2/df (p-value) \\
\hline \multicolumn{2}{|l|}{ Gender } & Frequency(percentages) & Frequency(percentages) \\
\hline Male & $4(40 \%)$ & $4(40 \%)$ & \multirow{2}{*}{$0.000 / 1(1.00)$} \\
\hline Female & $6(60 \%)$ & $6(60 \%)$ & \\
\hline \multicolumn{4}{|l|}{ Religion } \\
\hline Christianity & $10(100 \%)$ & $8(80 \%)$ & \multirow{2}{*}{$2.22 / 1(0.474)$} \\
\hline Islam & $0(0 \%)$ & $2(20 \%)$ & \\
\hline \multicolumn{4}{|l|}{ Education } \\
\hline NCE & $7(70 \%)$ & $7(70 \%)$ & \multirow{3}{*}{$1.200 / 2(0.549)$} \\
\hline B.Ed. & $2(20 \%)$ & $3(30 \%)$ & \\
\hline MSc & $1(10 \%)$ & $0(0 \%)$ & \\
\hline \multicolumn{4}{|l|}{ Specialization } \\
\hline None & $3(30 \%)$ & $0(0 \%)$ & \multirow{5}{*}{$6.67 / 4(0.155)$} \\
\hline Intellectual Disability & $0(0 \%)$ & $1(1 \%)$ & \\
\hline Hearing Impairment & $4(40 \%)$ & $8(80 \%)$ & \\
\hline PES & $1(10 \%)$ & $0(0 \%)$ & \\
\hline Visual Impairment & $2(20 \%)$ & $1(10 \%)$ & \\
\hline \multicolumn{4}{|c|}{ Previous training in FBA } \\
\hline Yes & $2(20 \%)$ & $0(0 \%)$ & \multirow{2}{*}{$2.22 / 1(0.474)$} \\
\hline No & $8(80 \%)$ & $10(100 \%)$ & \\
\hline
\end{tabular}

$\mathrm{NCE}=$ National Certificate in Education; B.Ed.=Bachelor of Education; MSc= Master of Science; PES= Primary Educational Studies 
Table 2.

BETWEEN-GROUP COMPARISON OF BASELINE SCORES ON OUTCOME MEASURES ACROSS INTERVENTION AND CONTROL GROUPS

\begin{tabular}{|c|c|c|c|c|}
\hline Parameters & Intervention group & Control group & $t / d f$ & P-value \\
\hline & $\mathrm{M}(\mathrm{SD})$ & $\mathrm{M}(\mathrm{SD})$ & & \\
\hline Total TSES Score & $125.50(26.03)$ & $136.00(20.13)$ & $-1.03 / 17$ & 0.315 \\
\hline Efficacy in student engagement & $42.80(9.70)$ & $48.10(8.60)$ & $-1.05 / 17$ & 0.310 \\
\hline Efficacy in Instructional strategies & $43.10(9.24)$ & $45.00(9.46)$ & $-.203 / 17$ & 0.841 \\
\hline Efficacy in Classroom Management & $39.60(8.17)$ & $46.70(9.44)$ & $-1.80 / 17$ & 0.089 \\
\hline Compassion Satisfaction Sub-scale of PQOLS & $39.10(3.60)$ & $36.70(8.34)$ & $0.84 / 17$ & 0.415 \\
\hline Burnout Sub-scale of PQOLS & $37.70(3.34)$ & $34.30(3.47)$ & $2.24 / 17$ & 0.038 \\
\hline Traumatic Stress sub-scale of PQOLS & $36.50(3.98)$ & $32.20(4.29)$ & $2.32 / 17$ & 0.032 \\
\hline
\end{tabular}

ces between mean scores in outcome measures between the intervention and control groups were compared at the baseline and post-intervention stages using T-tests. The effect of the training was determined by Analysis of Covariance (ANCOVA) using the post-intervention outcome measures as the dependent variables. For the latter analysis, partial eta squared $\left(\mathrm{np}^{2}\right)$ effect sizes were calculated with $.01, .06$ and .14 representing small, medium and large effect sizes respectively (Cohen, 1988). The level of significance was set at $\mathrm{p} \leq 0.05$.

\section{RESULTS}

The participants ranged in age between 22 years and 57 years $(M=42.50, S D=9.73)$. The mean number of years of teaching experience was 17.2 years $(S D=10.84)$. The years of experience as a special needs teacher ranged from 3-28 years with a median of 10.5 years. Most of the teachers were females $12(60 \%)$. The majority $14(70 \%)$ had a higher National Certificate in Education (NCE) qualification, five had a Bachelors Degree in Education, and one had a Masters Degree in Education. Most of the teachers specialized in working with students with hearing impairment $12(60 \%)$, while $3(15 \%)$ specialized in visual impairment, one specialized in intellectual disabilities. The remaining four had no main area of specialization.

The intervention and control groups did not differ significantly in their 'socio-demographic' characteristics including: gender, religion, education, and areas of specialization (Table 1).

\section{Effects of Intervention}

The pre- and post-intervention scores on outcome variables for the intervention and control groups are presented in Tables 2, 3, 4 and 5. Between-group comparison at baseline (Table 2), found no statistically significant differences in the intervention and control groups' total score on the self-efficacy scale or its sub-scales. However, the mean scores on the Burnout and Traumatic stress sub -scales of the PQOLS were significantly higher for the intervention group compared to the control group ( $\mathrm{p}=$ 0.038 and 0.032 respectively).

Table 3.

WITHIN-GROUP COMPARISON OF PRE AND POST INTERVENTION OUTCOME MEASURES FOR THE INTERVENTION GROUP

\begin{tabular}{|c|c|c|c|c|}
\hline Parameters & Pre-Intervention & Post-Intervention & $t / d f$ & P-value \\
\hline & $\mathrm{M}(\mathrm{SD})$ & $\mathrm{M}(\mathrm{SD})$ & & \\
\hline Total TSES Score & $125.33(26.54)$ & 156.44(30.36) & $-2.96 / 9$ & 0.016 \\
\hline Efficacy in student engagement & $43.00(10.27)$ & $52.44(9.58)$ & $-3.39 / 9$ & 0.008 \\
\hline Efficacy in Instructional strategies & $42.89(9.78)$ & $47.67(11.47)$ & $-1.49 / 9$ & 0.170 \\
\hline Efficacy in Classroom Management & $39.44(8.66)$ & $50.33(10.97)$ & $-3.51 / 9$ & 0.007 \\
\hline Compassion Satisfaction Sub-scale of PQOLS & $38.67(3.53)$ & $40.33(4.92)$ & $-1.19 / 9$ & 0.264 \\
\hline Burnout sub-scale of PQOLS & $37.11(2.93)$ & 29.22(2.73) & $5.42 / 9$ & 0.013 \\
\hline Traumatic Stress Sub-scale of the PQOLS & $36.44(4.22)$ & 19.67(6.82) & $5.79 / 9$ & 0.421 \\
\hline
\end{tabular}


Table 4

WITHIN-GROUP COMPARISON OF PRE AND POST INTERVENTION OUTCOME MEASURES FOR THE CONTROL GROUP

\begin{tabular}{|c|c|c|c|c|}
\hline Parameters & Pre-Intervention & Post-Intervention & t/df & P-value \\
\hline & $\mathrm{M}(\mathrm{SD})$ & $\mathrm{M}(\mathrm{SD})$ & & \\
\hline Total TSES & $135.89(21.35)$ & $131.11(21.35)$ & $1.67 / 8$ & 0.133 \\
\hline Efficacy in student engagement & $47.89(21.35)$ & $44.22(13.84)$ & $1.14 / 8$ & 0.289 \\
\hline Efficacy in Instructional strategies & $45.22(10.01)$ & $43.67(12.87)$ & $0.68 / 8$ & 0.519 \\
\hline Efficacy in Classroom Management & $47.00(9.96)$ & $43.22(10.56)$ & $2.22 / 8$ & 0.058 \\
\hline Compassion Satisfaction sub-scale of PQOLS & $36.33(8.16)$ & $41.89(4.96)$ & $-1.76 / 8$ & 0.117 \\
\hline Burnout sub-scale of PQOLS & $34.56(3.58)$ & $34.11(4.01)$ & $0.26 / 8$ & 0.804 \\
\hline Traumatic Stress sub-scale of PQOLS & $32.00(4.50)$ & $26.56(4.98)$ & $3.35 / 8$ & 0.010 \\
\hline
\end{tabular}

Within-group comparison for the intervention group (Table 3) showed a statistically significant increase in post-intervention scores when compared with baseline scores for TSES and the sub-scales of Efficacy in Student Engagement and Efficacy in Classroom Management. There was no significant increase in the Efficacy in Instructional Strategies of the teachers. In addition, the intervention group showed a statistically significant decrease in the Burnout sub-scale of the PQOLS.

As shown in Table 4, the control group showed no significant pre-post differences in TSES or the sub-scales and in total PQOLS or the subscales of Compassion or Burnout. However, the control group recorded a significant reduction in the Traumatic Stress sub-scale of the PQOLS.

Between-group comparison of the post-intervention scores of both groups (Table 5) showed that the intervention group scored significantly higher on TSES as well as Efficacy on Student Engagement, and Efficacy on Classroom Management when compared with the control group. There was no significant difference in the teachers' scores on Efficacy in Instructional Strategies between the two groups. Furthermore, the intervention group scored significantly lower than the control group on total PQOLS including the sub-scales of Burnout experience and Traumatic stress.

Further analysis (ANCOVA) to control for pre-intervention scores on total TSES and PQOLS scores showed significant differences between the intervention group and the control group on; the post-intervention scores for both the total self-efficacy and the burn out sub-scale of the PQOLS. The intervention group scored significantly higher on TSES $[\mathrm{F}(1,18)=8.95, \mathrm{p}=0.009$, partial eta squared $=0.36]$, and lower (i.e. more positive) on the Burnout sub-scale of PQOLS [F $(1,17)=9.82$, $\mathrm{p}=0.006$, partial eta squared $=0.380]$. The intervention groups' mean score on the Burnout sub-scale of PQOLS was more than one standard deviation lower than the control group after the intervention $[(29.30(2.58)$ vs 34.11(4.01)]. The absence of significant interactions indicated that the assumption of homogeneity of regression slopes was met.

Table 5.

BETWEEN-GROUP COMPARISON OF THE POST-INTERVENTION OUTCOME MEASURES BETWEEN THE INTERVENTION AND CONTROL GROUPS

\begin{tabular}{l|c|c|c|c}
\hline Parameters & Intervention group & Control group & t/df & P-value \\
\hline Total TSES Score & M(SD) & M(SD) & & \\
\hline Efficacy in student engagement & $156.00(33.58)$ & $131.11(33.59)$ & $2.33 / 17$ & 0.033 \\
\hline Efficacy in Instructional strategies & $54.20(10.60)$ & $44.22(13.84)$ & $2.46 / 17$ & 0.025 \\
\hline Efficacy in Classroom Management & $49.60(12.42)$ & $43.67(12.86)$ & $1.56 / 17$ & 0.138 \\
\hline Total Professional Quality of Life Scale (PQOLS) & $52.20(11.91)$ & $43.22(10.56)$ & $2.47 / 17$ & 0.024 \\
\hline Compassion Satisfaction Subscale of PQOLS & $89.60(5.30)$ & $102.56(10.18)$ & $-3.53 / 17$ & 0.003 \\
\hline Burnout Subscale of PQOLS & $40.60(4.72)$ & $41.89(4.96)$ & $-0.58 / 17$ & 0.569 \\
\hline Traumatic Stress subscale of PQOLS & $29.30(2.58)$ & $34.11(4.01)$ & $-3.14 / 17$ & 0.006 \\
\hline
\end{tabular}


Table 6.

COMPARISONS BETWEEN THE INTERVENTION GROUP AND CONTROL GROUP ON OUTCOME MEASURES

\begin{tabular}{|c|c|c|c|c|c|c|c|c|c|}
\hline & \multicolumn{3}{|c|}{ Intervention group $(n=10)$} & \multicolumn{3}{|c|}{ Control group $(n=10)$} & \multirow[b]{2}{*}{$\begin{array}{l}\text { F value } \\
(1,18)\end{array}$} & \multirow[b]{2}{*}{$\mathrm{P}$ value } & \multirow[b]{2}{*}{$\begin{array}{l}\text { Effect size } \\
\qquad(\mathrm{np} 2)\end{array}$} \\
\hline & Pre & Post & Difference & Pre & Post & Difference & & & \\
\hline Total TSES & $\begin{array}{l}125.33 \\
(26.54)\end{array}$ & $\begin{array}{l}156.44 \\
(30.36)\end{array}$ & 31.11 & $\begin{array}{l}135.89 \\
(20.13)\end{array}$ & $\begin{array}{l}131.11 \\
(21.35)\end{array}$ & -4.78 & 8.95 & 0.009 & 0.36 \\
\hline $\begin{array}{l}\text { Burnout subscale } \\
\text { PQOLS }\end{array}$ & $\begin{array}{l}37.11 \\
(2.93)\end{array}$ & $\begin{array}{l}29.22 \\
(2.73)\end{array}$ & -7.89 & $\begin{array}{l}34.56 \\
(3.58)\end{array}$ & $\begin{array}{l}34.11 \\
(4.01)\end{array}$ & -0.45 & 9.82 & 0.006 & 0.38 \\
\hline
\end{tabular}

\section{Effects of the Intervention}

\section{on Knowledge of the Participants}

At baseline, $90 \%$ of both the intervention and control groups had no or poor knowledge of challenging behaviours as only 2 of the teachers attempted to answer the question. There was no statistically significant difference in the groups' knowledge about challenging behaviours. However, at post intervention, $100 \%$ of the intervention, and none of the control group were rated as having fair or good knowledge of challenging behaviours. At baseline, all teachers in both the intervention and control groups had "No Knowledge" of FBA (except one who attempted the question but was rated as having "Poor Knowledge"). However, at post intervention, $70 \%$ of the teachers in the intervention group were rated as having fair or good knowledge of FBA, while none of the teachers in the control group were rated as having fair or good knowledge. This difference was statistically significant $(\mathrm{X} 2=10.58 ; \mathrm{df}=3 ; \mathrm{p}=0.014)$.

\section{Satisfaction with the Intervention Program}

Nine of the 10 teachers in the intervention group (90\%) rated the training as "excellent" while the remaining teacher rated it as "good". All the teachers indicated that the training had helped them to deal with their students' problems, and most of them (80\%) would "definitely" recommend the training to other teachers.

\section{DISCUSSION}

This two-session training programme on FBA for special education needs teachers significantly improved the intervention group's knowledge of FBA and their self-efficacy scores. Also, the intervention group had significantly lower burnout scores. The intervention group's post-treatment self-efficacy and burnout scores differed by more than one standard deviation for each outcome compared with the control group's scores. The special education teachers in the intervention group rated the FBA training programme highly. To our knowledge, this is the first study of its kind in sub-Saharan Africa. Thus, the study has made a contribution to the international diversity of the literature on FBA.

The findings of the current study are consistent with previous studies showing that: teachers' knowledge of FBA can be improved with training (Kunnavatana et al., 2013), teachers' self-efficacy is a malleable construct that can be enhanced by additional training such as on management of students' challenging behaviour (Zee \& Koomen, 2016), and improving teachers' skills and confidence in preventing and managing challenging behaviour can be associated with reduced feeling of burnout (Langher et al., 2017). A contribution of the current study is to start evidencing that these findings, which were established by previous studies in HICs, also apply in the different 'socio-cultural' and low-resource contexts of LMICs like Nigeria. While such similarities in the findings are not totally unexpected and might have been assumed, it is important that the current study empirically evaluated them in the context of a LMIC like Nigeria. This is because developing policies and practices in LMICs based on a non-contextualized evidence-base from HICs could be ineffective (Craig et al., 2013; Sweetland et al., 2014).

The finding of improved self-efficacy in the intervention group is particularly important. This is because higher teacher self-efficacy has been associated with several positive outcomes for both teachers and their students. Teachers with better self-efficacy cope better with stress, experience more satisfaction with their job, and are less likely to burnout and leave the profession (Zee \& Koomen, 2016). Similarly, higher teacher self-efficacy is associated with positive student experiences including better organized classrooms, a reduction in the incidence of challenging behaviours, and improved academic achie- 
vement (Zee \& Koomen, 2016). The link between training and improved teacher self-efficacy is underpinned by Bandura's social cognitive theory (Bandura, 1991). While this theory emphasizes that improvement in self -efficacy requires the individual to believe in their ability to achieve the goal, it acknowledges that equipping the person with the requisite knowledge and skills can help them to make a more positive evaluation of their likelihood of success; hence better self-efficacy. The opposite is also applicable, in that, lack of knowledge and skill can undermine the individual's self-evaluation about their own ability; hence lowering self-efficacy.

The additional finding of reduced burnout in the intervention group is also important. This is because teacher burnout is linked to adverse outcomes including: low job satisfaction, resentment, absenteeism, emotional exhaustion, reduced self-efficacy, and attrition from the profession (Ghanizadeh \& Jahedizadeh, 2015). A key risk factor for burnout is the expectation to complete tasks without having the requisite skills and support to successfully complete the task (Schaufeli, 2017).Thus, given the increased prevalence of challenging behaviours among children with special education needs, teaching affected children while having limited knowledge of how to prevent and manage challenging behaviours could be a recipe for burnout. In the current study, no teacher in the intervention or control group showed a good knowledge of challenging behaviour at baseline. However, this improved significantly in the intervention group, while it remained very low in the control group. It is therefore possible that by improving their knowledge, the training helped the intervention group to feel better equipped about preventing and managing challenging behaviours in the students, which in turn reduced their sense of burnout.

The main implication of this pilot study is the successful demonstration of the feasibility, efficacy and acceptability of inserting a short FBA-based training for special education teachers into their existing work schedule in the low-resource context of Nigeria. The short duration of the intervention, and the fact that it was "onsite" and built into the teachers' planned breaks meant that it did not disrupt their teaching activities or require extra human resources to "cover" the teachers' absence to attend the training. These factors contributed to the feasibility of the programme and thus make the programme more likely to be replicable and cost-effective in other similarly resource-constrained settings in Nigeria and in other LMICs.
While the findings of the current study are encouraging, they have to be viewed in the light of some limitations. First, the small sample size limits the 'generalizability' of the results, and may explain the lack of statistical significance in some outcome measures. Secondly, individual-level randomization of the participants was not possible due to the limited size of the sample frame. This means that other school-level factors may have contributed to the outcomes. Thirdly, the study did not assess the teachers' actual transition from knowledge to practice of managing challenging behaviours. Fourthly, the lack of a second follow-up data point means that sustainability of the treatment gains is uncertain.

In conclusion, this study has shown that training special education needs teachers on FBA-based strategies for the prevention and management of challenging behaviour is feasible in a low resource setting such as Nigeria. The intervention improved the teachers' self-efficacy and reduced their experience of burnout. Larger and adequately powered cluster randomized controlled studies are recommended to further explore the efficacy, 'generalizability', sustainability, and cost-effectiveness of these findings in these and similar settings.

\section{ACKNOWLEDGEMENT}

None.

DISCLOSURE STATEMENT

No potential conflict of interest

was reported by the authors.

\section{FUNDING}

None. 


\section{REFERENCES}

Adeyemo, S., Omoaregba, J., Aroyewun, B., Modebe, V., James, B., Uteh, B., \& Ezemokwe, C. (2015). Experiences of violence, compassion fatigue and compassion satisfaction on the professional quality of life of mental health professionals at a tertiary psychiatric facility in Nigeria. Open Science Journal of Clinical Medicine, 2(3), 69-73.

Bandura, A. (1986). Social foundations of thought and action (Vol. 1986). Prentice Hall.

Bandura, A. (1991). Social cognitive theory of self-regulation. Organizational Behavior and Human Decision Processes, 50(2), $248-287$. https://doi.org/https://doi.org/10.1016/0749-5978(91)90022-L

Bella-Awusah, T., Ani, C., Ajuwon, A., Omigbodun, O. J. C., \& Health, A. M. (2016). Effectiveness of brief school-based, group cognitive behavioural therapy for depressed adolescents in south west Nigeria. 21(1), 44-50.

Bello-Mojeed, M., Ani, C., Lagunju, I., \& Omigbodun, O. (2016). Feasibility of parent-mediated behavioural intervention for behavioural problems in children with Autism Spectrum Disorder in Nigeria: a pilot study. Child and Adolescent Psychiatry and Mental Health, 10(1), 28. https://doi.org/10.1186/s13034-016-0117-4

Brunsting, N. C., Sreckovic, M. A., \& Lane, K. L. (2014). Special education teacher burnout: A synthesis of research from 1979 to 2013. Education and treatment of children, 681-711.

Craig, P., Dieppe, P., Macintyre, S., Michie, S., Nazareth, I., \& Petticrew, M. (2013). Developing and evaluating complex interventions: The new medical research council guidance. International Journal of Nursing Studies, 50(5), 587-592. https://doi.org/10.1016/j.jinurstu.2012.09.010

Durowoju, E. O., \& Onuka, A. O. (2015). Teacher Self-Efficacy Enhancement and School Location: Implication for Students' Achievement in Economics in Senior Secondary School in Ibadan, Oyo State, Nigeria Journal of Education and Practice, 6(11), 109-115.

Emerson, E., \& Bromley, J. (1995). The form and function of challenging behaviours. Journal of Intellectual Disability Research, 39(5), 388-398.

Foran, D., Hoerger, M., Philpott, H., Jones, E. W., Hughes, J. C., \& Morgan, J. (2015). Using applied behaviour analysis as standard practice in a UK special needs school. 42(1), 34-52. https://doi.org/https://doi.org/10.1111/1467-8578.12088

Ghanizadeh, A., \& Jahedizadeh, S. (2015). Teacher burnout: A review of sources and ramifications. Journal of Education, Society and Behavioural Science, 6(1), 24-39.

Heath Jr, H., \& Smith, R. G. (2019). Precursor behavior and functional analysis: A brief review. 52(3), 804-810. https://doi.org/https://doi.org/10.1002/jaba.571

Hillel Lavian, R. (2015). Masters of weaving: The complex role of special education teachers. Teaching and Teacher Education, 21(1), 103-126.

Iwata, B. A., Smith, R. G., \& Michael, J. (2000). Current research on the influence of establishing operations on behavior in applied settings. Journal of Applied Behavior Analysis, 33(4), 411-418.

Joyce, O., Oladotun, A., Afolabi, A., \& Blessing, U. (2016). Compassion fatigue and adopted coping strategies of mental health service providers working in a regional psychiatric hospital in Nigeria. Journal of Behavior Therapy and Mental Health, 1(2), 38.

Kunnavatana, S. S., Bloom, S. E., Samaha, A. L., \& Dayton, E. (2013). Training Teachers to Conduct Trial-Based Functional Analyses. Behavior Modification, 37(6), 707-722. https://doi.org/10.1177/0145445513490950

Langher, V., Caputo, A., \& Ricci, M. E. (2017). The potential role of perceived support for reduction of special education teachers' burnout. International Journal of Educational Psychology, 6(2), 120-147.

Lloyd, B. P., Weaver, E. S., \& Staubitz, J. L. (2016). A Review of Functional Analysis Methods Conducted in Public School Classroom Settings. Journal of Behavioral Education, 25(3), 324-356. https://doi.org/10.1007/s10864-015-9243-y

Loman, S., \& Borgmeier, C. (2010). Practical Functional Behavioral Assessment Training Manual for School-Based Personnel.

Lunenburg, F. C. (2011). Self-efficacy in the workplace: Implications for motivation and performance. International journal of management, business, administration, 14(1), 1-6.

Mencl, J., Tay, L., Schwoerer, C. E., \& Drasgow, F. (2012). Evaluating Quantitative and Qualitative Types of Change: An Analysis of the Malleability of General and Specific Self-Efficacy Constructs and Measures. Journal of Leadership \& Organizational Studies,19(3), 378-391. https://doi.org/10.1177/1548051812442968

Olusanya, B. O., Davis, A. C., Wertlieb, D., Boo, N.-Y., Nair, M. K. C., Halpern, R., Kuper, H., Breinbauer, C., de Vries, P. J., Gladstone, M., Halfon, N., Kancherla, V., Mulaudzi, M. C., Kakooza-Mwesige, A., Ogbo, F. A., Olusanya, J. O., Williams, A. N., Wright, S. M., Manguerra, H., Smith, A., Echko, M., Ikeda, C., Liu, A., Millear, A., Ballesteros, K., Nichols, E., Erskine, H. E., Santomauro, D., Rankin, Z., Smith, M., Whiteford, H. A., Olsen, H. E., \& Kassebaum, N. J. (2018). Developmental disabilities among children younger than 5 years in 195 countries and territories, 1990\&\#x2013;2016: a systematic analysis for the Global Burden of Disease Study 2016. The Lancet Global Health, 6(10), e1100-e1121. https://doi.org/10.1016/S2214-109X(18)30309-7

Robinson, O. P., Bridges, S. A., Rollins, L. H., \& Schumacker, R. E. (2019). A study of the relation between special education burnout and job satisfaction. Journal of Research in Special Educational Needs, 19(4), 295-303.

Rotter, J. B. (1966). Generalized expectancies for internal versus external control of reinforcement. Psychological monographs: General applied, 80(1), 1.

Schaufeli, W. (2017). Applying the job demands-resources model. Organizational Dynamics, 2(46), 120-132. Stamm, B. (2005). The professional quality of life scale: Compassion satisfaction, burnout \& compassion fatigue/secondary trauma scales.

Lutherville, MD. In: Sidran Press. Retrieved from. http://www. isu. edu/irh/documents/proqol /ProQOL_Manual.pdf.

Stamm, B. H. (2010). The Concise ProQOL Manual (2nd ed.). Pocatello.

Sweetland, A. C., Oquendo, M. A., Sidat, M., Santos, P. F., Vermund, S. H., Duarte, C. S., Arbuckle, M., \& Wainberg, M. L. (2014). Closing the Mental Health Gap in Low-income Settings by Building Research Capacity: Perspectives from Mozambique. Annals of Global Health, 80(2), 126-133. https://doi.org/https://doi.org/10.1016/j.aogh.2014.04.014

Tschannen-Moran, M., \& Hoy, A. W. (2001). Teacher efficacy: capturing an elusive construct. Teaching and Teacher Education, 17(7), $783-805$. https://doi.org/http://dx.doi.org/10.1016/S0742-051X(01)00036-1

Zee, M., \& Koomen, H. M. (2016). Teacher self-efficacy and its effects on classroom processes, student academic adjustment, and teacher well-being: A synthesis of 40 years of research. Review of Educational research, 86(4), 981-1015. 